\title{
Low Frequency Modelling of Induction Heaters using Series Equivalent Circuit, Transformer Equivalent Circuit and Finite Element Analysis
}

\author{
Lisiate Takau and Pat Bodger \\ Department of Electrical and Computer Engineering \\ University of Canterbury \\ Christchurch, New Zealand
}

\begin{abstract}
Induction heating is a process where a varying magnetic field is used to heat a conductor or workpiece. When a piece of metal or conductor is placed near a magnetic field created by energising a coil of wire, the magnetic field transfers energy into the conductor, thus heating it up. This paper presents three methods for modelling induction heaters at mains frequency. These models are known as the series equivalent circuit (SEC) model, the transformer equivalent circuit (TEC) model and finite element analysis (FEA). The performances of these models are compared with experimental results for a demonstration induction heater. The FEA gives the best fit to the measured values and the TEC model gives better results than the SEC model.
\end{abstract}

Keywords-induction heating; workpiece; series equivalent circuit; transformer equivalent circuit; finite element analysis

\section{INTRODUCTION}

Induction heating is the heating of electrical conducting parts in a varying magnetic field. It involves electromagnetic induction, skin effect and heat transfer.

Electromagnetic induction describes the generation of a voltage in a conductor. It can happen in two entirely different ways; motional induction, where a conductor moves in a magnetic field, or transformer induction, where the circuit is stationary and the field varies with time [1]. Faraday's law of electromagnetic induction, which relates the generated voltage to the rate of change of flux, can take account of both effects.

Modelling an induction heater involves developing mathematical relationships of the physical process of electromagnetic induction. There are a number of models [2-7] which are considered valid at high frequencies only. However, at mains frequency, the SEC model [7] is often used. This looks at the flow of magnetic flux through the coil, airgap and workpiece of an induction heater and converts these into an equivalent electrical circuit, where all components are in series. The circuit components of the coil and workpiece resistance, and coil, airgap and workpiece reactances, cannot be interpreted as being actual values that can be measured. It is their combined series impedance that yields appropriate terminal current, power and power factor for a given applied voltage that is most important.
An alternative presented in this paper is the transformer equivalent circuit (TEC). This models the induction heater as a single turn secondary transformer. Its advantage is that the currents and voltages associated with components of the induction heater are what you would expect to measure on components of an actual induction heater. It thus allows better insight to the design and operation of the heater.

This paper presents the low frequency modelling of induction heaters using both the SEC and TEC models. Results from these two models are compared with those using FEA. The performance testing of an actual induction heater is then used to ascertain which model gives the best prediction of real performance.

\section{SEC MODEL OF INDUCTION HEATER}

This model of an induction heater is based on the series equivalent circuit depicted in Fig. 1[7]. This equivalent circuit has the resistance of the coil and workpiece and the reactances of the workpiece, air gap and coil $\left(R_{c}, R_{w}, X_{w}, X_{g}\right.$, and $\left.X_{c}\right)$ all in series.

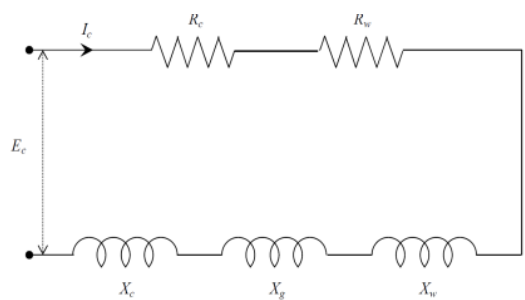

Fig. 1. Series equivalent circuit of induction heater [7]

The SEC method requires the induction heater to be designed by obtaining the values of the resistances and reactances of the coil, workpiece and the air gap between them, and then solving the circuit.

The series impedance is

$$
Z=\left(R_{w}+R_{c}\right)+j\left(X_{g}+X_{w}+X_{c}\right)
$$

where the components are

workpiece resistance 


$$
R_{w}=K\left(\mu_{r} p A_{w}\right)
$$

coil resistance

$$
R_{c}=K\left(\frac{k_{r} \pi d_{c} \delta_{c}}{2}\right)
$$

air gap resistance

$$
X_{g}=K\left(A_{g}\right)
$$

workpiece reactance

$$
X_{w}=K\left(\mu_{r} q A_{w}\right)
$$

coil reactance

$$
X_{c}=K\left(\frac{k_{r} \pi d_{c} \delta_{c}}{2}\right)
$$

and

$$
K=\frac{2 \pi f \mu_{0} N_{c}^{2}}{l_{c}}
$$

In these equations, $\mu_{r}$ is the relative permeability of the workpiece, $A_{w}$ is the cross-section of the workpiece, $d_{c}$ is the coil inner diameter, $\delta_{c}$ is the skin depth of the coil, $A_{g}$ is the air gap between the coil and the workpiece, $\mu_{0}$ is the permeability of free space $\left(4 \pi \times 10^{-7}\right), N_{c}$ is the coil turns, and $l_{c}$ is the coil length.

In the equation for the coil resistance and reactance, $k_{r}$ is a correction factor, allowing for the spacing between the turns ( $k_{r}$ lies between 1 and 1.5 , with 1.15 being a typical value). The expression (3) for the coil resistance is dependent on relative permeability and do not appear dimensionally correct. However, this is an expression of the model that allows terminal conditions to be calculated. The individual component value calculated should not be interpreted as what you would measure in practice.

The $p$ and $q$ factors in the equation for the workpiece resistance and reactance can be estimated from graphs or calculated from analytical expressions [7].

This set of equations is most relevant for long coils [8]. However, for short coils, a modification is suggested [8] whereby an external reactance $X_{e}$ is placed in parallel with the series combination of $R_{w}, X_{w}, X_{g}$, and $X_{c}$. This reactance represents the impedance of the end effects of the external flux path. It can be calculated from

$$
X_{e}=K\left(\frac{l_{c}}{R_{e}}\right)
$$

where $R_{e}$ is given in [8] as

$$
R_{e}=k_{c} \frac{1.80}{p_{c}}
$$

and $k_{c}$ is an empirical factor which is assumed to be 1 , and $p_{c}$ is the coil perimeter.

On the basis of the change in inductance of a cylindrical solenoid with length, it is possible to show that its external reluctance is practically independent of the length and equal approximately to $0.57 / d_{c}$ where $d_{c}$ is the coil diameter [8].

For an unknown reason, the addition of the short coil external reactance has since been regarded as "an ill-defined quantity" and "manifestly wrong" [7].

Hence, the long coil model is used in this paper. The addition of the short coil reactance would increase the current drawn from the supply and decrease the power factor.

\section{TEC MODEL OF INDUCTION HEATER}

An induction heater can be regarded as a special type of transformer with a single shorted turn secondary winding. The coil is the equivalent of a multiple turn primary winding, and the workpiece is the single turn secondary winding. The workpiece also performs the function of the transformer core, which the magnetic field generated by the coil passes through. Hence, a transformer equivalent circuit model is used to calculate the performance of the induction heater.

\section{A. Transformer equivalent circuit}

The TEC method determines the components of the circuit using the reverse design method [9]. It also calculates the performance of the induction heater.

The model of the induction heater is based on the transformer equivalent circuit depicted in Fig. 2. This circuit is based on an ideal transformer, with additional circuit elements to represent the practical deviations from the ideal. The TEC circuit in Fig. 2 is relevant for low frequency modelling of induction heaters.

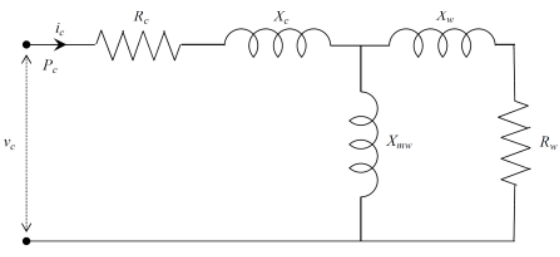

Fig. 2. Transformer equivalent circuit of induction heater [9].

The transformer equivalent circuit in Fig. 2 is more complicated than the series equivalent circuit in Fig. 1. The parallel impedance of the workpiece resistance and leakage reactance with the magnetizing reactance is

$$
Z_{w}=\frac{j X_{m w} \times\left(R_{w}+j X_{w}\right)}{\left(R_{w}+j\left(X_{w}+X_{m w}\right)\right)}
$$

and the total impedance is the complex value

$$
Z=\left(R_{c}+j X_{c}\right)+Z_{w}
$$

The performance of the induction heater is then obtained by applying a voltage to the coil and measuring the current, apparent power, real power and power factor.

In this model, $R_{w}$ represents the eddy current losses in the workpiece, which would normally be accounted for in the core of a transformer, $R_{c}$ is the resistance of the coil, and $X_{m w}$ is the magnetizing reactance which accounts for the current required to magnetize the core. Moreover, hysteresis losses, also normally a component of core losses in a transformer, are 
insignificant in induction heating. Hence the losses in the workpiece become resistance losses of the secondary winding.

The leakage reactance for each winding can be split between the coil and the workpiece as $X_{c}$ and $X_{w}$. The leakage reactances account for the imperfect magnetic field coupling between the coil and the workpiece.

The parameters of the equivalent circuit in Fig. 2 are calculated using the basic dimensions and physical characteristics of materials used, as per the reverse design method [9]. These are entered as known data and then the individual circuit components are calculated using magnetic and electric circuit component models.

Fig. 3 shows a cross-sectional profile of a multi-layer coil induction heater with a tube workpiece. All the symbols represent dimensions of the materials used in the construction of the heater, including the workpiece, insulation and the coil, where LW is the length of the workpiece, DW is the diameter of the workpiece, TW is the thickness of the workpiece, IWC is the workpiece/coil insulation thickness, WC is the diameter of the coil wire, WIC is the coil interlayer insulation, and DOC is the outside diameter of the coil.

The equivalent circuit components in Fig. 2 need to be modified as the flux path is open and not entirely constrained to be inside the core. Thus modifications to the calculation of reactance $X_{m w}$ is required as the core is no longer a closed loop. These are based on those derived for partial core transformers [10-11]. The winding resistance models $R_{c}$ and $R_{w}$ are maintained as they are not affected by the partial core configuration.

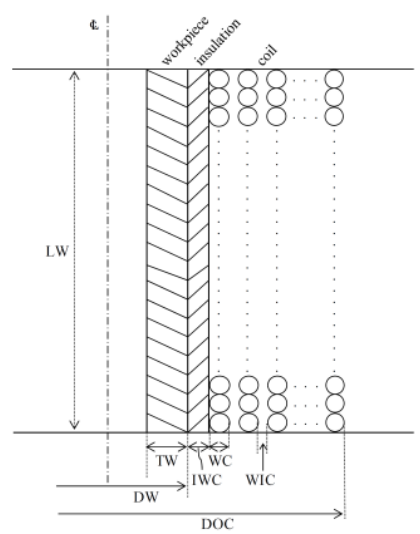

Fig. 3. Cross-section of a multi-layer coil induction heater with a tube workpiece.

\section{B. Coil resistance}

If $l_{c}$ is the length of the coil wire and $A_{c}$ is its crosssectional area, then the primary winding or coil resistance is given by

$$
R_{c}=\rho_{c} \frac{l_{c}}{A_{c}}
$$

where $\rho_{c}$ is the resistivity of the coil material. The value of the resistivity depends on the coil temperature as

$$
\rho_{c}=\left(1+\left(\Delta \rho\left(T_{c}-20\right)\right)\right) \rho_{20^{\circ} \mathrm{C}}
$$

where $\rho_{20^{\circ} \mathrm{C}}$ is the resistivity at $20^{\circ} \mathrm{C}, T_{c}$ is the coil temperature, and $\Delta \rho$ is the thermal resistivity coefficient. The resistivity of all metals is considered to vary linearly with temperature.

The calculation of the winding resistance $R_{c}$ also takes into account the coil skin depth and its effective cross sectional area. For the coil, the eddy current skin depth gives its effective thickness

$$
\delta_{c}=\sqrt{\frac{2 \rho_{c}}{\mu_{0} \mu_{r c} \omega}}
$$

where $\mu_{r c}$ is the relative permeability of the coil, and $\omega$ is the angular frequency $(2 \pi f)$. The coil effective cross sectional area is calculated using the diameter of the coil and its effective thickness.

\section{Workpiece magnetizing reactance}

The magnetizing reactance $X_{m w}$ for an open core induction heater is given in [11] as

$$
X_{m w}=\frac{\omega N_{c}^{2} \mu_{0} \mu_{r e} A_{w}}{l_{w}}
$$

where $\omega$ is the angular frequency, $N_{c}$ is the number of turns on the coil, $\mu_{0}$ is the permeability of free space $\left(4 \pi \times 10^{-7}\right)$, and $\mu_{r e}$ is the effective permeability of the magnetic flux path which includes the series combination of the workpiece and the return path, usually through air. $A_{w}$ is the effective crosssectional area of the workpiece, calculated using the skin depth $\delta_{w}$, and $l_{w}$ is the length of the workpiece.

\section{Coil/workpiece leakage reactance}

The coil and workpiece leakage reactances are calculated from the total leakage reactance which embodies the effects of both the coil and workpiece together. The total induction heater leakage reactance is given in [11] as

$$
X_{c w}=\frac{\omega N_{c}^{2} \mu_{0}}{l_{w}}\left[\frac{\left(w_{c} d_{c}+w_{w} d_{w}\right)}{3}+w_{c w} \nabla d\right]
$$

where $\omega$ is the angular frequency, $w_{c}$ is the mean circumferential length of the coil, $w_{w}$ is the mean circumferential length of the workpiece, $w_{c w}$ is the mean circumferential length of the space between the coil and the workpiece, and $\nabla d$ is the workpiece/coil insulation thickness.

The calculation of $X_{c w}$ does not separate the values of the coil and workpiece leakage reactances and they are usually assumed to be the same. Each of them is half of the total leakage reactance.

\section{E. Workpiece eddy current resistance}

The workpiece eddy current resistance referred to the coil is calculated using

$$
R_{w}=\rho_{w} \frac{l_{w e}}{A_{w e}} N_{c}^{2}
$$


where $\rho_{w}$ is the resistivity of the workpiece, $l_{w e}$ is the effective length of the eddy current flowing around the circumference of the workpiece, $A_{w e}$ is the effective cross-sectional area of the eddy current path, and $N_{c}$ is the number of coil turns.

The effective length and cross-sectional area of the eddy current path takes into account the skin depth in the workpiece

$$
\delta_{w}=\sqrt{\frac{2 \rho_{w}}{\mu_{0} \mu_{r e} \omega}}
$$

Thus

$$
l_{w e}=\pi\left(D_{w}-\delta_{w}\right)
$$

and

$$
A_{w e}=l_{w} \delta_{w}
$$

\section{F. Equivalent circuit performance for an experimental heater}

A coil of a small induction heater was constructed with the following parameters dimensions

TABLE I. COIL DimENSIONS

\begin{tabular}{|l|c|c|}
\hline Material & Copper & Unit \\
\hline Resistivity & 1.72 & $\left(\Omega \mathrm{m} \times 10^{-8}\right)$ \\
\hline Length & 208 & $\mathrm{~mm}$ \\
\hline Outside diameter & 114 & $\mathrm{~mm}$ \\
\hline Inside diameter & 83 & $\mathrm{~mm}$ \\
\hline Wire diameter & 1.7 & $\mathrm{~mm}$ \\
\hline Wire area & 2.27 & $\mathrm{~mm}^{2}$ \\
\hline Number of layers & 9 & - \\
\hline Turns per layer & 111 & - \\
\hline Number of turns & 999 & - \\
\hline Length of wire & 309 & $\mathrm{~m}$ \\
\hline Calculated resistance & 2.34 & $\Omega$ \\
\hline Measured resistance & 2.15 & $\Omega$ \\
\hline
\end{tabular}

A number of mild steel tubes of various diameters and thicknesses were cut to provide workpieces that fitted inside the coil. The dimensions of the workpieces are listed in Table II.

TABLE II. WORKPIECE DIMENSIONS

\begin{tabular}{|c|c|c|c|c|}
\hline $\begin{array}{l}\text { Work- } \\
\text { piece }\end{array}$ & Material & $\begin{array}{c}\text { Length } \\
(\mathbf{m m})\end{array}$ & $\begin{array}{c}\text { Diameter } \\
(\mathbf{m m})\end{array}$ & $\begin{array}{c}\text { Thickness } \\
(\mathbf{m m})\end{array}$ \\
\hline 1 & Mild steel & 250 & 44.3 & solid \\
\hline 2 & Mild steel & 250 & 44.5 & 12.6 \\
\hline 3 & Mild steel & 250 & 44.2 & 6.3 \\
\hline 4 & Mild steel & 250 & 48.3 & 3.3 \\
\hline 5 & Mild steel & 250 & 54.0 & 2.6 \\
\hline 6 & Mild steel & 250 & 70.0 & 2.0 \\
\hline 7 & Mild steel & 250 & 73.0 & solid \\
\hline
\end{tabular}

\section{G. Material properties}

For the sake of calculation, the physical characteristics of the copper coil and mild steel workpieces were taken as given in Table III. These are generic values as the actual values were unknown. There may be differences due to the metallurgy of their manufacture.

TABLE III. PhysicAl Properties of COPPER AND Mild STEEL

\begin{tabular}{|l|c|c|}
\hline Material & Copper & Mild steel \\
\hline Resistivity $\left(\Omega \mathrm{m} \times 10^{-8}\right)$ & 1.72 & 16 \\
\hline
\end{tabular}

\begin{tabular}{|l|c|c|}
\hline Relative permeability & 1 & 750 \\
\hline Skin depth at $50 \mathrm{~Hz}(\mathrm{~mm})$ & 9.3 & 1.0 \\
\hline
\end{tabular}

Having obtained all the parameters of the equivalent circuits from the material characteristics and dimensions, the performance of the heater could be calculated by solving the equivalent circuit equations and determining the current, power and power factor for a given applied voltage. In addition, efficiencies, voltage gradients, voltages per turn and current densities could be calculated.

\section{CAlCUlated PERFormance}

To check the performance of the induction heaters, two programs were written in Matlab for the SEC long coil and the TEC models to perform all the above calculations. The various

\begin{tabular}{|c|c|c|c|}
\hline \multicolumn{2}{|c|}{ Circuit component } & \multicolumn{2}{|c|}{ Value(@) } \\
\hline SEC & TEC & SEC & TEC \\
\hline$R_{c}$ & $R_{c}$ & 0.241 & 2.372 \\
\hline$R_{w}$ & $R_{w}$ & 9.346 & 47.753 \\
\hline$X_{c}$ & $X_{c}$ & 0.241 & 2.513 \\
\hline$X_{w}$ & $X_{w}$ & 9.510 & 2.513 \\
\hline$X_{g}$ & $X_{m w}$ & 2.321 & 31.873 \\
\hline
\end{tabular}
components of the SEC and TEC are given in Table IV.

TABLE IV. COMPONENT VALUES FOR THE SEC AND TEC MODELS

The value of the coil resistance should not be taken too literally. Indeed, for the actual as-build induction heater of the dimensions listed in Table I, the coil resistance was measured to be $2.15 \Omega$. Rather, it is the total circuit that gives rise to terminal conditions that is of importance.

By contrast, the component values of the TEC are very different from those of the SEC. This is because the TEC is very different.

The coil resistance is about 10 times that previously calculated. It is a better indication of what was measured using a resistance meter applied to the coil conductor.

The workpiece resistance (referred to the coil) is also much larger (5 times) than that calculated from the SEC model. The actual resistance is very low, $4.8 \mu \Omega$. Again the value should be a reasonable indication of what you could measure. The workpiece resistance is much larger than the coil resistance and hence the efficiency should be high.

For this example, the leakage reactances are relatively small, which indicates that there is good coupling between the coil and the workpiece. A relatively long coil length and small coil/workpiece interspace ensures this. Thus the TEC model gives a useful measure of this feature. The value is about the same as the air gap reactance used in the series model, although here the value is used twice, for both the coil and the workpiece, as only the combined effect can be calculated. The TEC model is less dominated by the leakage (air gap) reactance.

The workpiece magnetizing reactance is much larger than the workpiece reactance used before. There is no direct correlation between this and the workpiece reactance calculated from the SEC model. 
Tables V and VI show the calculated performances of the induction heaters at a $100 \mathrm{~V}$ supply.

TABLE V. CALCULATED PERFORMANCE USING SEC LONG COIL MODEL

\begin{tabular}{|l|l|l|l|l|l|l|l|}
\hline $\begin{array}{l}\text { Work } \\
\text {-piece }\end{array}$ & $\begin{array}{l}\text { Voltage } \\
(\mathbf{V})\end{array}$ & $\begin{array}{l}\text { Current } \\
(\mathbf{A})\end{array}$ & $\begin{array}{l}\text { Flux } \\
\text { density(T) }\end{array}$ & $\begin{array}{l}\text { Coil } \\
\text { loss(W) }\end{array}$ & $\begin{array}{l}\text { Workpiece } \\
\text { loss(W) }\end{array}$ & $\begin{array}{l}\text { Apparent } \\
\text { power(VA) }\end{array}$ & $\begin{array}{l}\text { Power } \\
\text { factor }\end{array}$ \\
\hline 1 & 100 & 6.9 & 3.2 & 7.6 & 438.6 & 692.1 & 0.6 \\
\hline 2 & 100 & 6.9 & 3.2 & 7.6 & 438.3 & 691.7 & 0.6 \\
\hline 3 & 100 & 6.9 & 3.2 & 7.6 & 438.8 & 692.3 & 0.6 \\
\hline 4 & 100 & 6.9 & 2.9 & 7.9 & 431.7 & 685.1 & 0.6 \\
\hline 5 & 100 & 6.8 & 2.6 & 8.5 & 422.2 & 675.8 & 0.6 \\
\hline 6 & 100 & 6.5 & 2.0 & 9.9 & 397.6 & 652.7 & 0.6 \\
\hline 7 & 100 & 6.5 & 1.9 & 10.2 & 393.3 & 648.7 & 0.6 \\
\hline
\end{tabular}

TABLE VI. CALCULATED PERFORMANCE USING TEC MODEL

\begin{tabular}{|l|l|l|l|l|l|l|l|}
\hline $\begin{array}{l}\text { Work } \\
\text {-piece }\end{array}$ & $\begin{array}{l}\text { Voltage } \\
\text { (V) }\end{array}$ & $\begin{array}{l}\text { Current } \\
\text { (A) }\end{array}$ & $\begin{array}{l}\text { Flux } \\
\text { density(T) }\end{array}$ & $\begin{array}{l}\text { Coil- } \\
\text { loss(W) }\end{array}$ & $\begin{array}{l}\text { Workpiece } \\
\text { loss(W) }\end{array}$ & $\begin{array}{l}\text { Apparent } \\
\text { power(VA) }\end{array}$ & $\begin{array}{l}\text { Power } \\
\text { factor }\end{array}$ \\
\hline 1 & 100 & 3.9 & 3.2 & 26.7 & 100.9 & 397.2 & 0.3 \\
\hline 2 & 100 & 3.9 & 3.2 & 26.6 & 100.5 & 396.3 & 0.3 \\
\hline 3 & 100 & 3.9 & 3.2 & 26.7 & 101.2 & 397.7 & 0.3 \\
\hline 4 & 100 & 3.8 & 2.9 & 25.8 & 92.2 & 380.2 & 0.3 \\
\hline 5 & 100 & 3.6 & 2.6 & 24.8 & 81.9 & 359.7 & 0.3 \\
\hline 6 & 100 & 3.2 & 2.0 & 23.1 & 62.3 & 317.0 & 0.3 \\
\hline 7 & 100 & 3.1 & 1.9 & 22.9 & 59.6 & 310.7 & 0.3 \\
\hline
\end{tabular}

The calculated performances from the SEC model are significantly higher than the TEC model in terms of current, apparent power and workpiece loss. The same is not true for the coil loss. The power factors from the SEC model are twice those calculated from the TEC model. Both models yield the same flux density, but in all cases this is calculated to be a value significantly above that of the likely saturation value for mild steel.

For the SEC model, the short coil reactance, as suggested by Baker [8], was calculated to be $57.4 \Omega$. This is much higher than any of the other components and therefore had little effect on the results, increasing the current by about $0.1 \mathrm{~A}$ and insignificantly changing the power factor.

As a modification to the TEC model, the permeability of the workpiece is reduced until the flux density is below the saturation point. This means that the skin depth increases. The magnetizing reactance and the workpiece eddy current resistance are adjusted to account for this.

If the flux penetrates beyond the thickness of the workpiece, then part of the flux flows inside the workpiece. The parallel combination of this reluctance and that of the workpiece must be taken into account in calculating the workpiece magnetization reactance. Table VII shows the calculated performance of the induction heater for operation at the saturation point set at a realistic $1.7 \mathrm{~T}$. The workpiece losses are higher than those given in Table VI but still significantly lower than those calculated using the SEC model. The power factors have, in general, increased.

TABLE VII. CALCULATED PERFORMANCE USING TEC MODEL BELOW THE SATURATION POINT

\begin{tabular}{|l|l|l|l|l|l|l|l|}
\hline $\begin{array}{l}\text { Work } \\
\text {-piece }\end{array}$ & $\begin{array}{l}\text { Voltage } \\
\text { (V) }\end{array}$ & $\begin{array}{l}\text { Current } \\
\text { (A) }\end{array}$ & $\begin{array}{l}\text { Flux } \\
\text { density(T) }\end{array}$ & $\begin{array}{l}\text { Coil } \\
\text { loss(W) }\end{array}$ & $\begin{array}{l}\text { Workpiece } \\
\text { loss(W) }\end{array}$ & $\begin{array}{l}\text { Apparent } \\
\text { power(VA) }\end{array}$ & $\begin{array}{l}\text { Power } \\
\text { factor }\end{array}$ \\
\hline 1 & 100 & 4.3 & 1.7 & 30.8 & 190.9 & 397.2 & 0.5 \\
\hline 2 & 100 & 4.3 & 1.7 & 30.6 & 189.2 & 396.3 & 0.5 \\
\hline 3 & 100 & 4.3 & 1.7 & 30.9 & 191.9 & 397.7 & 0.5 \\
\hline 4 & 100 & 3.9 & 1.7 & 27.6 & 159.5 & 380.2 & 0.5 \\
\hline
\end{tabular}

\begin{tabular}{|l|l|l|l|l|l|l|l|}
\hline 5 & 100 & 3.6 & 1.7 & 24.9 & 126.5 & 359.7 & 0.4 \\
\hline 6 & 100 & 3.1 & 1.7 & 22.3 & 73.6 & 311.7 & 0.3 \\
\hline 7 & 100 & 3.1 & 1.7 & 22.3 & 67.4 & 306.3 & 0.3 \\
\hline
\end{tabular}

\section{FINITE ELEMENT ANALYSIS}

MagNet software [12] was then used to create a 2D FEA model of the actual heater. The coil and workpiece were modelled using axial symmetry. Because of its circular symmetry, only a quarter model of the coil and workpiece were required. The coil dimensions provided are internal diameter, outside diameter and length. Each coil was modelled as a block of solid copper that covers all the turns of that winding. The workpiece was created using its inside and outside diameters and length as well. The workpiece was modelled as a single block of isotropic linear material with relative permeability of 750 and a resistivity of $16 \times 10^{-8} \Omega \mathrm{m}$. Fig. 4(a) shows a quarter model of the coil and workpiece of the heater for workpiece 1 .

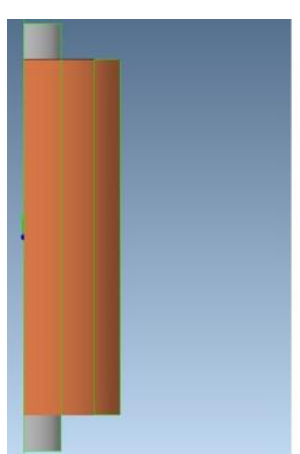

(a)

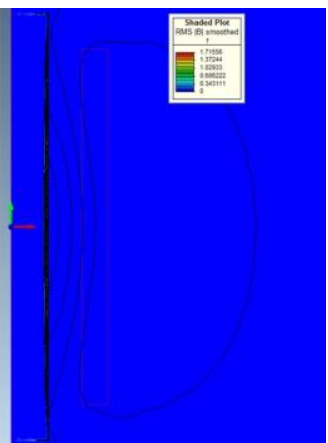

(b)
Fig. 4. Quarter model of workpiece 1(a); flux plot of workpiece 1(b).

A quarter-model of the flux plot of the heater using workpiece 1 is shown in Fig. 4(b). The coil is energised with a $100 \mathrm{~V}$ supply. The maximum flux density in the workpiece is $1.7 \mathrm{~T}$ which is equal to the set value for the TEC model. A small amount of fringing can be seen at both ends of the workpiece. Most of the flux is concentrated in the skin depth of the workpiece, which is about $1 \mathrm{~mm}$ for mild steel.

Table VIII shows the performance of the experimental heater at $100 \mathrm{~V}$ supply, calculated using FEA. All the workpiece maximum flux densities are at the assumed knee point of the $B-H$ curve. The coil current and coil and workpiece losses are, in general, lower than those given in Tables V and VII.

TABLE VIII. CALCULATED PERFORMANCE USING FEA

\begin{tabular}{|l|l|l|l|l|l|l|l|}
\hline $\begin{array}{l}\text { Work } \\
\text {-piece }\end{array}$ & $\begin{array}{l}\text { Voltage } \\
\text { (V) }\end{array}$ & $\begin{array}{l}\text { Current } \\
(\mathbf{A})\end{array}$ & $\begin{array}{l}\text { Flux } \\
\text { density(T) }\end{array}$ & $\begin{array}{l}\text { Coil } \\
\text { loss(W) }\end{array}$ & $\begin{array}{l}\text { Workpiece } \\
\text { loss(W) }\end{array}$ & $\begin{array}{l}\text { Apparent } \\
\text { power(VA) }\end{array}$ & $\begin{array}{l}\text { Power } \\
\text { factor }\end{array}$ \\
\hline 1 & 100 & 2.3 & 1.7 & 8.6 & 55.5 & 230 & 0.3 \\
\hline 2 & 100 & 2.3 & 1.7 & 8.4 & 55.4 & 230 & 0.3 \\
\hline 3 & 100 & 2.3 & 1.7 & 8.6 & 55.9 & 230 & 0.3 \\
\hline 4 & 100 & 2.1 & 1.7 & 7.1 & 49.4 & 210 & 0.3 \\
\hline 5 & 100 & 1.9 & 1.7 & 6.1 & 42.0 & 190 & 0.3 \\
\hline 6 & 100 & 1.5 & 1.7 & 3.9 & 28.0 & 150 & 0.2 \\
\hline 7 & 100 & 1.5 & 1.7 & 3.5 & 26.2 & 150 & 0.2 \\
\hline
\end{tabular}




\section{MEASURED PERFORMANCE}

The test set-up consisted of a variac, power meter, current clamp and a multimeter, with a thermocouple to monitor the temperature of the workpiece.

The perfomance of the experimental heater is given in Table IX. The ambient temperature during the test was between $20^{\circ} \mathrm{C}$ to $25^{\circ} \mathrm{C}$.

TABLE IX. MEASURED PERFORMANCE OF INDUCTION HEATERS

\begin{tabular}{|l|l|l|l|l|l|l|}
\hline $\begin{array}{l}\text { Work- } \\
\text { piece }\end{array}$ & $\begin{array}{l}\text { Voltage } \\
(\mathbf{V})\end{array}$ & $\begin{array}{l}\text { Current } \\
(\mathbf{A})\end{array}$ & $\begin{array}{l}\text { Coil } \\
\text { loss(W) }\end{array}$ & $\begin{array}{l}\text { Workpiece } \\
\text { loss(W) }\end{array}$ & $\begin{array}{l}\text { Apparent } \\
\text { power(VA) }\end{array}$ & $\begin{array}{l}\text { Power } \\
\text { factor }\end{array}$ \\
\hline 1 & 100 & 1.9 & 7.8 & 84.2 & 199 & 0.5 \\
\hline 2 & 100 & 1.6 & 5.5 & 62.5 & 167 & 0.4 \\
\hline 3 & 100 & 1.6 & 5.5 & 62.5 & 170 & 0.4 \\
\hline 4 & 100 & 1.9 & 7.8 & 91.2 & 196 & 0.5 \\
\hline 5 & 100 & 1.7 & 6.2 & 81.8 & 174 & 0.5 \\
\hline 6 & 100 & 1.1 & 2.6 & 48.4 & 117 & 0.4 \\
\hline 7 & 100 & 1.0 & 2.2 & 46.9 & 109 & 0.5 \\
\hline
\end{tabular}

The flux density cannot be measured. The coil loss is calculated using the measured coil resistance and the measured current. The workpiece loss is then calculated by subtracting the coil loss from the measured real power.

The currents are lower than those calculated by any of the three models. The measured coil losses are close to those calculated from the SEC and FEA models, but quite dissimilar to those from the TEC model because of the current differences.

The workpiece losses are between those calculated using the TEC and FEA models, and much less than those calculated by the SEC model.

The power factors are close to those from the TEC and FEA models and slightly less than those from the SEC model.

\section{DISCUSSION}

The SEC and TEC models give very disparate results for this design. The SEC model does not accommodate workpiece saturation, while the TEC model can allow for this. Even so, the TEC model results, while much closer to the measured values for the workpieces tested, are still significantly higher than the measured values.

These differences may be explained by the materials having different physical characteristics than the generic values chosen, but also the applicability of using lumped circuit equivalents of open core devices.

The SEC and TEC models are seen to be useful closed form analytical expressions which can easily be programmed using readily available advanced calculators or spreadsheet software. However, their accuracies are such that they yield design guides only rather than definitive performance results.

The Finite Element Analysis yields results much closer to those measured and is preferred. However, such modelling relies on proprietary software which may be more difficult to access, making it less amenable for teaching purposes.
However, it does provide more accurate modelling, at least for the case presented.

One of the purposes of this model comparison is to justify the selection of both the TEC and FEA models to predict the performance of Transduction heaters, a combination of transformer and induction heaters, to be introduced in a separate paper. Transduction heaters have not been modelled using the SEC approach.

\section{CONCLUSION}

This paper presents the low frequency modelling of induction heaters using the SEC and TEC models and also FEA. The performances of the induction heaters from these models are compared to the measured performances of an experimental heater for a variety of sizes of mild steel workpieces.

The calculated performances of the TEC model shows significantly lower values in terms of the current and workpiece losses compared to the SEC model. However, both the SEC and TEC models yield performance measures significantly different from those measured and need refinement to improve their performance predictions.

The FEA model gives much closer values to those measured.

\section{REFERENCES}

[1] J.D.Edwards, "Course in Electromechanics", Infolytica Corporation, Montreal, 2004

[2] C.V. Dodd and W.E. Deeds, "Analytical Solutions to Eddy-Current Probe-Coil Problems", Journal of Applied Physics, vol. 39, no 6, pp 2829-2838, May 1968.

[3] C.V. Dodd, C.C. Cheng, W.E. Deed, "Induction Coils Coaxial with an arbitrary number of cylindrical conductors", Journal of Applied Physics, vol. 45, no 2, pp 638-647, Feb. 1974.

[4] K.V. Namjoshi, J.D. Lavers, P.K. Jain, "Vector potential due to a circular loop in a toroidal cavity in a high-permeability core", IEEE Transactions on Magnetics, vol. 37, no 6, pp 3900-3906, Nov. 2001.

[5] K.V. Namjoshi, P.P. Biringer, "Current distribution in exciting coil conductors in cross-field heating systems", IEEE Transactions on Magnetics, vol. 29, no 2, pp 1570-1573, Mar. 1993.

[6] A.M. Hussein, P.P. Biringer, "Closed-form solution for the induction heating problem with rotational symmetry", Journal of Applied Physics, vol. 72, no. 1, pp 265-269, July 1992.

[7] J. Davies, and P.Simpson “ Induction Heating Handbook”, McGraw-Hill Book Company (UK) Ltd, Maidenhead, Berkshire, England, 1979.

[8] R.M. Baker, "Design and calculation of induction heating coils", Transactions of the American Institute of Electrical Engineers, March 1957, pp. 31-40.

[9] Bodger, P.S., and Liew M.C., "Reverse as-built transformer design method", Int. J. Elect. Enging. Educ., v39, n1, January 2002, pp. 42-53.

[10] Liew, M.C. and Bodger P.S., "Partial core transformer design using reverse modelling techniques", IEE Proceedings - Electric Power Applications, v148(6), 2001, pp. 513-519

[11] Liew, M.C. and Bodger, P.S., "Applying a reverse design modelling technique to partial core transformers", J. Electrical and Electronics Engineering, Australia, v22, n1, 2002, pp. 85-92.

[12] MagNet 7.3 (2012), Finite-element package for electromagnetic analysis, Infolytica Corporation, Montreal. 